\title{
New microbial surface-active compounds: the ultimate alternative to chemical surfactants?
}

\author{
Eduardo J. Gudiña, Ana I. Rodrigues, José A. Teixeira and Lígia R. Rodrigues \\ CEB - Centre of Biological Engineering, University of Minho 4710-057 Braga, Portugal \\ E-mail: egudina@deb.uminho.pt
}

\section{ABSTRACT}

Surface active compounds (SACS) produced by microorganisms are attracting a pronounced interest due to their potential advantages over synthetic counterparts, and to the fact that they could replace some of the synthetics in many environmental and industrial applications. Bioemulsifier production by a Paenibacillus strain isolated from crude oil was studied. The bioemulsifier was produced using sucrose with and without adding hydrocarbons (paraffin or crude oil) under aerobic and anaerobic conditions at $40^{\circ} \mathrm{C}$. It formed stable emulsions with several hydrocarbons, exhibiting similar or better emulsifying activity when compared with chemical SACs, and its emulsifying ability was not affected by exposure to high salinities (up to $300 \mathrm{~g} / \mathrm{l}$ ), high temperatures (100-121으) or a wide range of $\mathrm{pH}$ values (2-13). In addition, it presented low toxicity and high biodegradability when compared with chemical surfactants, implying a greater environmental compatibility. A preliminary chemical characterization by Fourier Transform Infrared Spectroscopy (FT-IR), proton and carbon nuclear magnetic resonance $\left({ }^{1} \mathrm{H} N M R\right.$ and ${ }^{13} \mathrm{C} C P$-MAS NMR) and size exclusion chromatography indicated that the bioemulsifier is a low molecular weight oligosaccharide-lipid complex. To the best of our knowledge, bioemulsifier production by a Paenibacillus strain has not been previously reported. This is also the first description of a low molecular weight bioemulsifier. The features of this novel bioemulsifier make it an interesting biotechnological product for many environmental and industrial applications.

\section{INTRODUCTION}

Surface active compounds (SACs) comprise a major component of many of the everyday products we use. They can be found in detergents, laundry formulations, household cleaning products, cosmetics, herbicides or pesticides, and are also used in bioremediation, agriculture, food, 


\section{SIMPÓSIO NACIONAL DE BIOPROCESSOS \\ XI SIMPÓSIO DE HIDRÓLISE ENZIMÁTICA DE BIOMASSA}

01 a 04 de setembro de 2015

Fortaleza, Ceará, Brasil

pharmaceutical, textile, paper or the petroleum industries, among others. Traditionally, SACs (including linear alkylbenzene sulfonates (LAS), fatty alcohol ethoxylates (FAE) or lauryl ether sulfonates (LES)) have been produced from petrochemical or oleochemical feedstock. Nowadays, due to the increasing environmental awareness, the demand for SACs obtained from bio-based resources (such as alkyl polyglucosides (APG) and alkyl polyglucamides) is increasing (Vaz et al., 2012).

SACs produced by microorganisms are attracting a pronounced interest due to their potential advantages over synthetic counterparts, and to the fact that they could replace some of the synthetics in many environmental and industrial applications. They exhibit similar or better performances when compared with chemically synthesized SACs, and because of their biological origin, they are considered less toxic and more easily biodegradable, thus implying a greater environmental compatibility (Gudiña et al., 2015a).

Despite the clear advantages and the potential applications of microbial SACs, their overall use is hampered by high production costs and their limited structural variation in contrast to chemically produced SACs, where variations can be introduced by simply changing the building blocks (Henkel et al., 2012). Structural variation is essential for SACs to find applications in a very broad range of sectors. It is expected that a huge variety of SACs producers are still undetected in nature, so the lack of variability can be partially tackled by screening for novel and better wild-type producers.

In this work, a novel bioemulsifier produced by a new Paenibacillus sp. strain obtained from a crude oil sample was isolated and characterized. Bioemulsifier production was studied using a mineral medium with and without hydrocarbons, under aerobic and anaerobic conditions. Furthermore, its toxicity and biodegradability were studied and compared with chemical surfactants.

\section{RESULTS AND DISCUSSION}

A bacterial strain (isolate \#510) obtained from a crude oil sample after an enrichment process was found to produce a promising emulsifying agent, with emulsifying indexes (using $n$-hexadecane) higher than $50 \%$. The partial sequence obtained from its 16S rRNA gene exhibited the highest similarity (99\%) with different species belonging to the genus Paenibacillus. According to these results, the isolate was designated as Paenibacillus sp. \#510. The strain was deposited on Micoteca da Universidade do Minho (MUM) culture collection under the reference number MUM 14.03.

Bioemulsifier production by this isolate was evaluated using a mineral medium (MSS), with and without sucrose $(20 \mathrm{~g} / \mathrm{l})$, supplemented or not with hydrocarbons (paraffin or crude oil $(5 \%, \mathrm{w} / \mathrm{v})$ ), under aerobic and anaerobic conditions, at $40^{\circ} \mathrm{C}$ and $120 \mathrm{rpm}$. Bioemulsifier production was observed in all the conditions tested, except in the media without sucrose.

Bioemulsifier production was higher under aerobic conditions when compared with the anaerobic condition, and in both cases, it was induced by the addition of paraffin or crude oil to the culture 


\section{SIMPÓSIO NACIONAL DE BIOPROCESSOS \\ XI SIMPÓSIO DE HIDRÓLISE ENZIMÁTICA DE BIOMASSA}

01 a 04 de setembro de 2015

Fortaleza, Ceará, Brasil

medium. In all the cases, bioemulsifier production was found to be growth-associated. The highest bioemulsifier production (7.9 g/l after 168 hours of growth) was achieved using the medium MSS supplemented with paraffin under aerobic conditions. Regarding the anaerobic conditions, the highest bioemulsifier production (5.6 g/l after 240 hours of growth) was also achieved using the medium MSS supplemented with paraffin. This is the first report of bioemulsifier production by a Paenibacillus strain.

Similarly to other bioemulsifiers produced by different bacteria, yeasts and filamentous fungi, the bioemulsifier produced by Paenibacillus sp. \#510 did not reduce the surface tension (Colin et al., 2013). Although less studied than biosurfactants, bioemulsifiers, due to their properties, could replace some of the chemically synthesized emulsifiers in bioremediation, enhanced oil recovery, clean-up of oil contaminated pipes and vessels, as additives in cleaning products and laundry formulations, and as emulsion-stabilizing agents in the food, cosmetic or pharmaceutical industries.

A broad spectrum of emulsifying activity is essential for the use of a bioemulsifier in industrial processes, such as bioremediation, treatment of industrial effluents, oil tank clean-up, emulsionfacilitated oil transport or emulsion-based fuels, because those processes include different mixtures of hydrophobic compounds. The bioemulsifier produced by Paenibacillus sp. \#510 formed stable emulsions (for up to 1 month at 40ㅇ) with aliphatic ( $n$-hexadecane, $n$-hexane, chloroform, dichloromethane, ethyl acetate) and aromatic (toluene, xylene) hydrocarbons, as well as with hydrocarbon mixtures (crude oil, paraffin), thus representing a potential candidate to be used in a variety of biotechnological and industrial applications. Furthermore, the applicability of SACs in several fields depends on their stability at different temperatures, salinities and $\mathrm{pH}$ values. The bioemulsifier herein studied was stable at high $\mathrm{NaCl}$ concentrations (up to $300 \mathrm{~g} / \mathrm{l}$ ), a wide range of $\mathrm{pH}$ values (2-13), and high temperatures (100-121으), which makes it useful for applications involving extreme environmental conditions.

The toxicity of the bioemulsifier herein studied and three chemical SACs (Glucopone ${ }^{\circledR} 650$, Findet ${ }^{\circledR} 1214 N / 23$, LAS) was assessed by measuring the reduction of light emission by Vibrio fisheri when exposed to different concentrations of SACs for 30 minutes as compared to the control (distilled water). The bioemulsifier exhibited lower toxicity as compared to the synthetic SACS studied. Also the biodegradability of the same chemical SACs and the bioemulsifier in liquid medium was assessed by respirometric assays, measuring the Biochemical Oxygen Demand (BOD) and the Chemical Oxygen Demand (COD). The results obtained indicated that the bioemulsifier is more easily biodegradable when compared with the chemical SACs. Toxicity and biodegradability are important features when evaluating the environmental risk associated with the use of SACs. The lower toxicity and the higher biodegradability of this bioemulsifier when compared with chemical surfactants studied make it a greener option for environmental applications.

A preliminary chemical characterization by Fourier Transform Infrared Spectroscopy (FT-IR), proton and carbon nuclear magnetic resonance $\left({ }^{1} \mathrm{H}\right.$ NMR and $\left.{ }^{13} \mathrm{C} C P-M A S ~ N M R\right)$ and size exclusion chromatography indicated that the bioemulsifier is a low molecular weight oligosaccharide-lipid complex, in contrast with other known bioemulsifiers, which are high molecular weight polymers (Gudiña et al., 2015b). 


\section{SIMPÓSIO NACIONAL DE BIOPROCESSOS \\ XI SIMPÓSIO DE HIDRÓLISE ENZIMÁTICA DE BIOMASSA}

\section{CONCLUSIONS}

The production of a bioemulsifier by a novel Paenibacillus strain isolated from crude oil was reported. The preliminary chemical characterization revealed that it is a low molecular weight oligosaccharide-lipid complex. To our knowledge, the production of a low molecular weight bioemulsifier by a Paenibacillus strain has not been previously reported. The bioemulsifier was found to form stable emulsions with a variety of hydrophobic compounds and was not affected by exposure to extreme environmental conditions. Furthermore, the bioemulsifier exhibited a good environmental compatibility as can be concluded from the toxicity and biodegradability results obtained. Altogether, the features of this novel bioemulsifier make it an interesting biotechnological product for many environmental and industrial applications.

\section{ACKNOWLEDGEMENTS}

The authors acknowledge the financial support from the projects BIOCLEAN - Desenvolvimento de produtos contendo surfactantes microbianos para limpeza e desinfeção de superfícies industriais e domésticas. Ref.: QREN- n.o 2013/030215, and NCMICROBIOS - Desenvolvimento de bioprocessos usando microrganismos não convencionais para a produção de biosurfactantes - Convénio FCTCNPq № 17/2013 - Ref.: Projecto no 6818.

\section{REFERENCES}

Colin, V.L., Pereira, C.E., Villegas, L.B., Amoroso, M.J., Abate, C.M., 2013. Production and partial characterization of bioemulsifier from a chromium-resistant actinobacteria. Chemosphere 90, 1372-1378.

Gudiña, E.J., Pereira, J.F.B., Costa, R., Evtuguin, D.V., Coutinho, J.A.P., Teixeira, J.A., Rodrigues, L.R., 2015b. Novel bioemulsifier produced by a Paenibacillus strain isolated from crude oil. Microb. Cell Fact. 14, 14. doi:10.1186/s12934-015-0197-5.

Gudiña, E.J., Rodrigues, A.I., Alves, E., Domingues, M.R., Teixeira, J.A., Rodrigues, L.R., 2015a. Bioconversion of agro-industrial by-products in rhamnolipids toward applications in enhanced oil recovery and bioremediation. Bioresour. Technol. 177, 87-93.

Henkel, M., Müller, M.M., Kügler, J.H., Lovaglio, R.B., Contiero, J., Syldatk, C., Hausmann, R., 2012. Rhamnolipids as biosurfactants from renewable resources: concepts for next-generation rhamnolipid production. Process Biochem. 47, 1207-1219. 


\section{SIMPÓSIO NACIONAL DE BIOPROCESSOS \\ XI SIMPÓSIO DE HIDRÓLISE ENZIMÁTICA DE BIOMASSA}

01 a 04 de setembro de 2015

Fortaleza, Ceará, Brasil

Vaz, D.A., Gudiña, E.J., Alameda, E.J., Teixeira, J.A., Rodrigues, L.R., 2012. Performance of a biosurfactant produced by a Bacillus subtilis strain isolated from crude oil samples as compared to commercial chemical surfactants. Colloids Surf. B 89, 167-174. 